\title{
TRANSMISSION OF THE COMMON COLD TO VOLUNTEERS UNDER CONTROLLED CONDITIONS. IV. SPECIFIC IMMUNITY TO THE COMMON COLD *
}

\author{
BY GEORGE GEE JACKSON AND HARRY F. DOWLING \\ (From the Department of Medicine and the Research and Educational Hospitals, University \\ of Illinois College of Medicine, Chicago, Ill.)
}

(Submitted for publication December 10, 1958; accepted January 5, 1959)

Although the common cold is the most prevalent illness of humans, information on the antigenicity of the infectious agents and the immune response of the host to the infection has been difficult to obtain. Epidemiologic investigations have led to divergent hypotheses. The frequent repetition of colds, on the one hand, has suggested little or no immunity to reinfection. On the other hand, the diminution or disappearance of colds among isolated populations, even in an arctic climate, is compatible with the belief that persons develop immunity to specific common cold agents $(1,2)$. Analysis of the influence of age upon susceptibility also is inconclusive with regard to acquired immunity to the common cold. The frequency of common colds tends to decline with age beyond childhood (3-5), but in a survey of colds within a group of families apparent evidence of brief immunity was observed after infection only among children (3).

Transmission of the common cold to volunteers by filtered nasal secretions or nasopharyngeal washings offers the most direct approach to the problem. Several groups of investigators have shown that the common cold can be successfully transmitted to volunteers, but almost always it has been impossible to infect all of them. The incidence of experimental colds has been about 35 to 50 per cent $(6,7)$. The basis for susceptibility or resistance is not known but might be specific immunity. In previous studies we have shown that the infectivity of filtered infectious nasal secretions can be neutralized by the globulin fraction, but not by albumin, from pooled human plasma (8).

* These studies were carried out under the sponsorship of the Commission on Acute Respiratory Diseases, Armed Forces Epidemiological Board, and were supported in part by the Office of the Surgeon General, Department of the Army, and in part by grants from the Lederle Laboratries Division, American Cyanamid Company, and from Charles Pfizer \& Company, Inc.
Andrewes has reported that serum of persons convalescent from the common cold has the capacity to inactivate the common cold virus (9). These data suggest that specific neutralizing antibody might in fact be developed during recovery from the common cold. In this paper, data are presented that show a significant degree of specific immunity among volunteers to a second challenge with the same infectious nasal secretion and a lack of immunity following challenge with a different nasal secretion.

\section{MATERIALS AND METHODS}

The details of the volunteer experiments have been published previously (7). Each nasal secretion that was given to volunteers was collected during the months from January through April from a different donor during a nonfebrile, coryzal illness which had the characteristics of a common cold. The secretions were stored in a refrigerator at $-90^{\circ} \mathrm{F}$. Later they were thawed and homogenized with an equal volume of Hanks salt solution. The sediment was separated by centrifugation. The supernatant was diluted until the final concentration of nasal secrtion was $1: 5$. The solution was then filtered through a sintered glass or porcelain (Selas 02) bacterial filter. The filtrate was diluted with an equal portion of a solution of stabilizing protein which was a five per cent solution of human type $O$ hemoglobin until 1954, and since that time, a one per cent solution of yeast extract. Aliquots of the secretions were tested in a $1: 2$ or $1: 10$ dilution of the original secretion for recognizable viruses in embryonated eggs, suckling and adult mice and monolayers of Hela and monkey kidney cells in tissue culture. Paired sera from the donors were not always obtained but sera from volunteers given each agent were tested by complement fixation and/or neutralization tests for common respiratory viruses.

The volunteers were almost all students enrolled in nursing, medicine, dentistry or pharmacy. They had been free from symptoms of a spontaneous or experimental cold for at least six weeks. Subjects were placed in groups at the beginning of the experiment. The infectious challenge, which was instilled into each nostril of the recumbent subject, was $0.2 \mathrm{ml}$. of a $1: 100$ final dilution of nasal secretion or the control challenge consisting 
TABLE I

Transmission of the common cold to volunteers

\begin{tabular}{lccccc}
\hline \hline & & \multicolumn{3}{c}{ Experimental result } \\
\cline { 3 - 5 } \multicolumn{1}{c}{ Challenge } & $\begin{array}{c}\text { Number } \\
\text { challenged* }\end{array}$ & $\begin{array}{l}\text { No } \\
\text { cold }\end{array}$ & Cold & $\begin{array}{r}\% \\
\text { colds }\end{array}$ \\
\hline $\begin{array}{l}\text { Nasal secretion } \\
\text { Buffer }\end{array}$ & 1,034 & 585 & 449 & 42 \\
$\begin{array}{l}\text { Significance } \\
\text { of difference }\end{array}$ & 696 & 626 & 70 & 10 \\
& $x^{2}=377, p=<0.001$ & &
\end{tabular}

* Only the initial challenge with any one secretion is included.

of the same volume of buffered salt solution. The groups were kept isolated for $\mathbf{3 0}$ minutes before dismissal. They were requested to avoid close association with other volunteers and all persons with respiratory illness. Sneezing, headache, malaise, chilliness, sore throat, nasal discharge, nasal obstruction and cough were elicited from the subject and graded for the day prior to challenge and each day for six days after challenge by a person unaware of the nature of the nasal instillation. The increase in these symptoms over the amount present on the day of the challenge was totalled at the end of the week and designated the symptom score. The decision as to whether the subject had developed a cold was based upon three criteria: total symptom score, subjective recognition of a "cold" and the degree of increased nasal discharge (7).

\section{RESULTS}

The results of the initial challenge of 1,034 subjects given one of five infectious nasal secretions are given in Table I. On the basis of the criteria outlined above, 449 , or 42 per cent, of them developed a cold. Among 696 control subjects simultaneously given buffered salt solution, only 70 , or 10 per cent, developed a cold. The difference in the incidence of illness following the two types of inocula is highly significant.
TABLE II

Infectivity among volunteers of different nasal secretions from donors with a common cold

\begin{tabular}{cccccrrr}
\hline \hline \multicolumn{2}{c}{ Nasal secretion } & & & \multicolumn{3}{c}{ Experimental results } \\
\cline { 7 - 8 } $\begin{array}{c}\text { Year } \\
\text { recovered }\end{array}$ & Code & & $\begin{array}{c}\text { Number } \\
\text { challenged* }\end{array}$ & & $\begin{array}{c}\text { No } \\
\text { cold }\end{array}$ & Cold & $\begin{array}{c}\% \\
\text { colds }\end{array}$ \\
\hline 1953 & 69 & 219 & & 136 & 83 & 38 \\
1954 & 111 & & 185 & & 116 & 69 & 37 \\
1955 & 127 & & 261 & & 164 & 97 & 37 \\
1956 & 142 & & 231 & & 114 & 117 & 51 \\
1957 & 154 & & 138 & & 55 & 83 & 60
\end{tabular}

* Only the initial challenge with any one secretion is included.

The five secretions were collected in successive years from 1953 to 1957 . Each secretion was given to more than 100 volunteers. The infectivity of the individual secretions in the initial challenge of volunteers varied from 37 to 60 per cent as shown in Table II. For each secretion, the amount of illness transmitted was highly significant compared with control subjects.

The susceptibility on initial challenge of volunteers when they are arranged into groups according to whether the subject participated in one or several experiments and received the same or a different secretion is shown in Table III. Colds developed in 43 per cent of 660 persons given only one infectious challenge. Among 144 volunteers who were later rechallenged with the same secretion, 71 , or 49 per cent, developed a cold from the initial challenge and 13 , or 9 per cent, developed a cold from rechallenge; among 115 subjects subsequently given different secretions, 35 per cent had colds from the initial challenge and 43 per cent from the second secretion. Thus, natural host factors, if contributory, would appear to have

TABLE III

Comparison of the susceptibility of different groups of volunteers to the initial challenge with an infectious nasal secretion

\begin{tabular}{|c|c|c|c|c|c|}
\hline \multirow[b]{2}{*}{ Number of participations } & \multirow{2}{*}{$\begin{array}{l}\text { Number } \\
\text { challenged }\end{array}$} & \multirow{2}{*}{$\begin{array}{l}\text { Sequence of } \\
\text { challenge }\end{array}$} & \multicolumn{3}{|c|}{ Experimental result } \\
\hline & & & No cold & Cold & $\%$ colds \\
\hline 1 only & 660 & Initial & 373 & 287 & 43 \\
\hline $\begin{array}{l}2 \text { or more with same } \\
\text { nasal secretion }\end{array}$ & $\begin{array}{l}144 \\
144\end{array}$ & $\begin{array}{l}\text { Initial } \\
\text { Rechallenge with } \\
\text { same secretion }\end{array}$ & $\begin{array}{r}73 \\
131\end{array}$ & 71 & $\begin{array}{l}49 \\
9)\end{array}$ \\
\hline $\begin{array}{l}2 \text { or more with different } \\
\text { nasal secretion }\end{array}$ & $\begin{array}{l}115 \\
115\end{array}$ & $\begin{array}{l}\text { Initial } \\
\text { Second nasal } \\
\text { secretion }\end{array}$ & 65 & 41 & $\begin{array}{l}35 \\
43)\end{array}$ \\
\hline
\end{tabular}


TABLE IV

Response of volunteers to two successive challenges with the same infectious nasal secretion

\begin{tabular}{|c|c|c|c|c|c|c|c|c|c|}
\hline \multirow[b]{3}{*}{ Line } & \multirow{2}{*}{\multicolumn{2}{|c|}{$\begin{array}{c}\text { Result of experimental } \\
\text { challenges }\end{array}$}} & \multicolumn{7}{|c|}{ Number of volunteers who received: } \\
\hline & & & \multicolumn{5}{|c|}{ Nasal secretion no.: } & \multirow{2}{*}{$\begin{array}{l}\text { Any nasal } \\
\text { secretion }\end{array}$} & \multirow[b]{2}{*}{ Buffer } \\
\hline & challenge & Rechallenge & 69 & 111 & 127 & 142 & 154 & & \\
\hline \multirow[t]{3}{*}{$\begin{array}{l}1 \\
2 \\
3 \\
4\end{array}$} & $\begin{array}{l}\text { No cold } \\
\text { No cold } \\
\text { Cold } \\
\text { Cold }\end{array}$ & $\begin{array}{l}\text { No cold } \\
\text { Cold } \\
\text { No cold } \\
\text { Cold }\end{array}$ & $\begin{array}{l}2 \\
0 \\
0 \\
0\end{array}$ & $\begin{array}{l}3 \\
1 \\
6 \\
1\end{array}$ & $\begin{array}{r}24 \\
3 \\
14 \\
1\end{array}$ & $\begin{array}{r}16 \\
3 \\
17 \\
0\end{array}$ & $\begin{array}{r}21 \\
0 \\
28 \\
4\end{array}$ & $\begin{array}{r}66(90 \%) \\
7(10 \%) \\
65(92 \%) \\
6 \quad(8 \%)\end{array}$ & $\begin{array}{r}48 \\
2 \\
1 \\
0\end{array}$ \\
\hline & \multicolumn{2}{|c|}{ Total subjects challenged } & 2 & 11 & 42 & 36 & 53 & 144 & 51 \\
\hline & \multicolumn{2}{|c|}{$\begin{array}{l}\text { Colds developing af ter } \\
\text { initial challenge } \\
\text { (Lines } 3 \text { and } 4)\end{array}$} & & & & & & & \\
\hline \multirow[t]{2}{*}{$\begin{array}{l}5 \\
6\end{array}$} & & $\begin{array}{l}\text { Number } \\
\text { Per cent }\end{array}$ & $\begin{array}{l}\mathbf{0} \\
\mathbf{0}\end{array}$ & $\begin{array}{r}7 \\
64\end{array}$ & $\begin{array}{l}15 \\
36\end{array}$ & $\begin{array}{l}17 \\
47\end{array}$ & $\begin{array}{l}32 \\
60\end{array}$ & $\begin{array}{l}71 \\
49\end{array}$ & $\begin{array}{l}1 \\
2\end{array}$ \\
\hline & \multicolumn{2}{|c|}{$\begin{array}{l}\text { Colds developing after } \\
\text { rechallenge } \\
\text { (Lines } 2 \text { and } 4 \text { ) }\end{array}$} & & & & & & & \\
\hline $\begin{array}{l}7 \\
8\end{array}$ & & $\begin{array}{l}\text { Number } \\
\text { Per cent }\end{array}$ & $\begin{array}{l}\mathbf{0} \\
\mathbf{0}\end{array}$ & $\begin{array}{r}2 \\
18\end{array}$ & $\begin{array}{r}4 \\
10\end{array}$ & $\begin{array}{l}3 \\
8\end{array}$ & $\begin{array}{l}4 \\
8\end{array}$ & $\begin{array}{r}13 \\
9\end{array}$ & $\begin{array}{l}2 \\
4\end{array}$ \\
\hline 9 & \multicolumn{2}{|c|}{$\begin{array}{l}\text { Significance of difference } \\
\text { Initial vs. rechallenge }\end{array}$} & & $<0.05$ & $<0.01$ & $<0.001$ & $<0.001$ & $<0.001$ & Not sig. \\
\hline
\end{tabular}

favored greater susceptibility in the group rechallenged with the same secretion.

The results of rechallenge with the same secretion are shown in Table IV. Among 73 volunteers (Lines 1 and 2) who had no cold following the initial challenge, 66 , or 90 per cent, (Line 1) were again immune upon rechallenge. Among 71 others (Lines 3 and 4 ) who developed a cold from the initial challenge with one of the five secretions, 65 , or 92 per cent (Line 3), were immune upon rechallenge with the same secretion. The mean interval between challenges was 15.2 weeks with a range of 3 to 45 weeks. The difference in susceptibility to the initial challenge and the subsequent rechallenge is highly significant $(p=<0.001)$, and since 10 per cent spontaneous colds were observed among a large number of subjects given a buffered salt solution (Table I) the results might represent complete immunity to rechallenge with the same agent.

A similar pattern of induced immunity was observed for each of the individual secretions. The per cent of colds after rechallenge (Table IV, Line 8) was always considerably less than after the initial challenge (Line 6). The difference was statistically significant (Line 9) beyond the chance level of 0.001 for the single Secretions 154 and
142, beyond the 0.01 level for Secretion 127 and the 0.05 level for Secretion 111 .

A survey of the six subjects who developed a cold after both of two successive exposures to the same secretion (Table IV, Line 4) showed that in four of them the second of the two colds was definitely of lesser severity. The symptom score was only one-third to one-half that of the initial illness. The two remaining subjects developed symptoms on the first day of the experiment and had fever, neither of which were characteristic of the experimentally transmitted illness.

Among the seven volunteers who developed a cold only after the second of two challenges with the same secretion (Table IV, Line 2), the time of onset and character of the illness indicated that two of them almost surely had a cold which originated outside of the experiment and five appeared to have been genuinely susceptible and developed a cold from the second challenge only. The interval between challenges for those subjects who had a cold upon rechallenge (Lines 2 and 4 ) was 7 to 34 weeks, statistically the same as for the entire group.

The data were analyzed to determine whether the decreased infectivity observed upon rechallenge might be an artifact owing to diminished 
TABLE V

The simultaneous infectivity of stored nasal secretions in different types of volunteers participating in the same experiments

\begin{tabular}{|c|c|c|c|c|c|}
\hline \multirow[b]{2}{*}{$\begin{array}{l}\text { Nasal } \\
\text { secretion }\end{array}$} & \multicolumn{2}{|c|}{$\begin{array}{l}\text { Volunteers } \\
\text { receiving initial } \\
\text { challenge }\end{array}$} & \multicolumn{2}{|c|}{$\begin{array}{l}\text { Volunteers } \\
\text { receiving a } \\
\text { rechallenge }\end{array}$} & \multirow{2}{*}{ 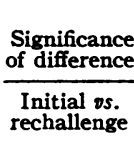 } \\
\hline & No. & $\begin{array}{c}\% \\
\text { colds }\end{array}$ & No. & $\begin{array}{c}\% \\
\text { colds }\end{array}$ & \\
\hline $\begin{array}{l}111 \\
127 \\
142 \\
154\end{array}$ & $\begin{array}{l}53 \\
96 \\
89 \\
90\end{array}$ & $\begin{array}{l}30 \\
42 \\
47 \\
60\end{array}$ & $\begin{array}{l}11 \\
35 \\
25 \\
33\end{array}$ & $\begin{array}{r}18 \\
11 \\
12 \\
6\end{array}$ & $\begin{array}{l}\text { Not sig. } \\
<0.001 \\
<0.001 \\
<0.001\end{array}$ \\
\hline Sum & 314 & 48 & 104 & 10 & $<0.001$ \\
\hline
\end{tabular}

infectivity of the secretions upon storage. That this was not the case is shown by the comparison of infectivity among subjects given an initial challenge simultaneously with those who were rechallenged (Table V). The number of observations is smaller than the total number who were rechallenged since all of the experiments did not contain both types of subjects. The differences in infectivity of the secretion between initial and rechallenged volunteers in the same experiments are highly significant for each of the secretions for which 25 to 35 observations were available for comparison.

Evidence regarding the specificity of the different secretions and the similarity of the volunteers except for their acquired specific immunity was obtained by comparing the results among subjects rechallenged with the same secretion and those who were later challenged with a different secretion. The comparison is shown in Figure 1. Volunteers were observed to be immune to rechallenge with the same secretion, shown by the left hand pair of bars in the lower two panels, regardless of the clinical result of the initial challenge, shown in the upper panel. This was a significantly different result than was observed among volunteers who were rechallenged with a different secretion illustrated by the right hand pair of bars in the lower two panels. The latter subjects were just as susceptible to the second challenge as the general population, as observed from the results among persons who participated in a single experiment.

Susceptibility to the second secretion also was independent of whether the initial challenge caused a cold or no cold. Among 74 subjects who were

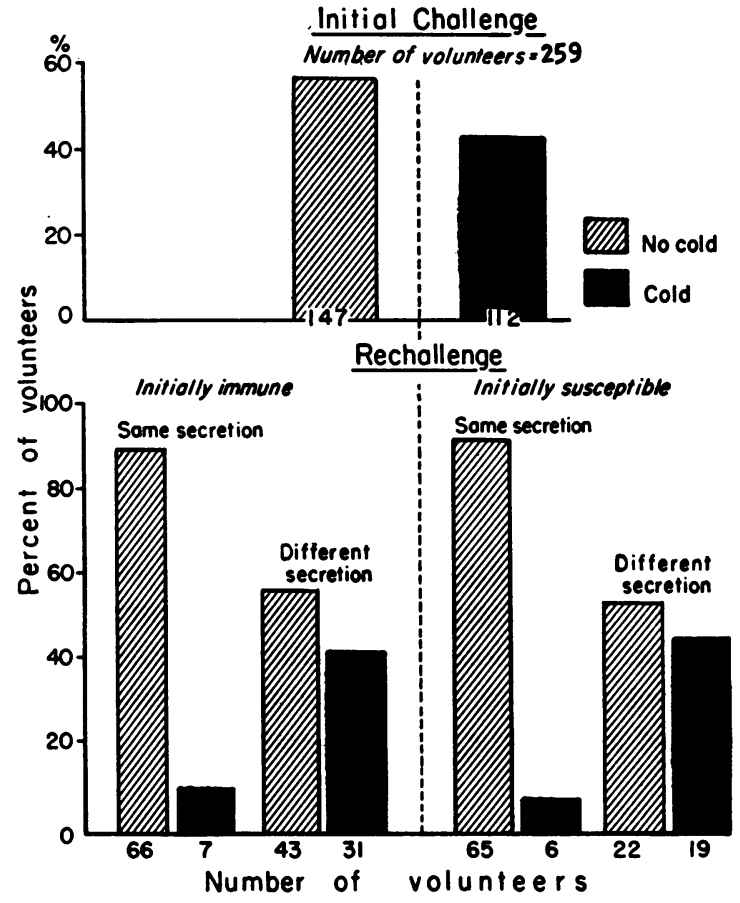

Fig. 1. Response of Volunteers to Two Challenges with Infectious Nasal Secretion

initially immune to one secretion and were later challenged with a different secretion, 31 , or 40 per cent, developed a cold. Similarly, among 41 initially susceptible volunteers who had a cold after the first challenge and were subsequently challenged with a different secretion, 19, or 46 per cent, developed a cold. These results are statistically the same and are also nearly identical to the results of the initial challenge of the same subjects. They are significantly different from the results of rechallenge with the same secretion among either the initially immune or initially susceptible volunteers.

The sequence of administration of different secretions was examined for evidence of cross-immunity among persons given more than one infectious secretion. The data are shown in Table VI. The mean interval between challenges was 30.6 weeks with a range of 10 to 74 weeks. No interrelationship is apparent. The order in which the different secretions were used was dependent upon their time of recovery, and thus all possible sequences were not examined. Overall, colds were observed in 43 per cent of volunteers after the latter of two agents given in sequence, and in 
TABLE VI

Lack of acquired cross-immunity to common cold nasal secretions

\begin{tabular}{|c|c|c|c|c|c|c|c|}
\hline \multicolumn{4}{|c|}{ Sequential challenge } & & & & \multirow{3}{*}{$\begin{array}{c}\begin{array}{c}\text { Significance } \\
\text { of difference }\end{array} \\
\begin{array}{c}\text { Sequence vs. } \\
\text { single challenge }\end{array}\end{array}$} \\
\hline $\begin{array}{c}\text { Prior } \\
\text { challenge }\end{array}$ & \multicolumn{3}{|c|}{ Later challenge } & \multicolumn{3}{|c|}{ Single challenge only } & \\
\hline Secretion & Secretion & $\begin{array}{l}\text { Number } \\
\text { challenged }\end{array}$ & $\%$ colds & Secretion & $\begin{array}{l}\text { Number } \\
\text { challenged }\end{array}$ & $\%$ colds & \\
\hline $\begin{array}{c}69 \\
69 \text { or } 111 \\
69,111 \text { or } 127 \\
127 \text { or } 142\end{array}$ & $\begin{array}{l}111 \\
127 \\
142 \\
154\end{array}$ & $\begin{array}{r}15 \\
61 \\
36 \\
3\end{array}$ & $\begin{array}{l}20 \\
31 \\
72 \\
67\end{array}$ & $\begin{array}{l}111 \\
127 \\
142 \\
154\end{array}$ & $\begin{array}{r}108 \\
127 \\
158 \\
84\end{array}$ & $\begin{array}{l}37 \\
39 \\
46 \\
58\end{array}$ & $\begin{array}{l}\text { None } \\
\text { None } \\
<0.05 \\
\text { None }\end{array}$ \\
\hline Total & & 115 & 43 & & 477 & 45 & None \\
\hline
\end{tabular}

45 per cent among others who were challenged only with the latter agent. Thus, in contrast to the specific protection to rechallenge conferred by any one secretion, no cross-protection was demonstrated among the different secretions.

\section{DISCUSSION}

The data are quite conclusive evidence for the development of specific immunity to a second cold from the same infectious nasal secretion under the conditions of the experiments. They imply that the five agents from secretions collected in successive years are immunologically distinct and that one-third to two-thirds of the volunteer population was, initially, specifically immune to each of the agents. Previously, analysis of the incubation period had suggested that some of the agents were different from one another (7). These findings raise many questions as to how they are related to common experience with respiratory infections, previous epidemiologic and clinical investigations, and finally as to the identity and number of common cold viruses.

The first critique should consider the validity of the methods by which the data were obtained. In any infection the response of the primary host to an infectious challenge is considered the ultimate test for immunity. Volunteer studies satisfy this requirement. The basic protocols for the replicate experiments were similar, so that all subjects were challenged in the same manner and with the same volume and dilution of the filtered nasal secretion (7). The differences were not caused by season, nonspecific characteristics of the volunteers, nor a change in the secretions upon storage. We have not used any pooled secretions nor repassaged agents.

The common cold is principally an afebrile, subjective, coryzal illness (7). There is therefore some margin of error in the proper designation of volunteers with an experimental cold. In these experiments, we adhered rigidly to criteria previously outlined as delineating an experimental cold (7). Also, the experiments were controlled by the inclusion of randomly-selected volunteers who received only buffered saline. The statistical differences observed greatly exceeded any error from the experimental design. Finally, since the volunteer population included 1,730 subjects in approximately 90 separate experiments performed over a period of more than five years, variations in individual experiments were minimized.

One phase of the experiments that was not ideal is the lack of isolation of the subjects before and during the experiments. Some of the illnesses observed were possibly from community contacts, and the community exposure might have produced colds or immunity that would make the data impure. Such "wild" colds would have tended to give a falsely high proportion of colds. The significant finding in these experiments was a low incidence of colds among particular groups of volunteers. The observed immunity pertained to only one secretion and was therefore specific whether it was acquired experimentally or from outside contacts. The high degree of statistical significance in the results, when analyzed either by simultaneous comparison of initial volunteers with those who were being rechallenged, or by longitudinal comparison of volunteers who were rechallenged with those who participated only 
once and with uninfected control subjects, strongly suggests that concomitant community infections were unimportant in the interpretation of the results.

The duration of the specific immunity cannot be estimated beyond the 3 to 45 weeks observed. Thus, immunity might not last from one season of respiratory diseases to another; on the other hand, if protection from reinfection is based upon the development of specific antibody, immunity might last much longer.

With regard to prior epidemiologic and investigative data, the principle of specific immunity would be an adequate basis upon which to explain the findings in the classic observations in Greenland (1) and at Spitsbergen (2) and the historical report of acute upper respiratory diseases among inhabitants of the arctic island of St. Kilda (10). Specific antibody is the presumed basis for the neutralization of the infectious secretion by human globulin (8) and by serum from persons convalescent from a common cold (9).

In the detailed studies of respiratory illnesses among Cleveland families, if secondary attack rates were taken as an index of the relative immune status of the individual, the descending order of immunity was observed to be fathers, mothers and older school children, school children aged less than 6 years and, finally, preschool children. The findings of Lidwell and Sommerville (3) and Buck (11) were essentially the same. The latter investigator found some indication of decreased susceptibility to colds among preschool children and among adults during the two months following a cold but not among infants or among children aged 5 to 14 years.

Likewise, Reid, Williams and Hirch (12) noted some indication of short-term immunity during an epidemic of colds among office workers.

Badger and his associates $(5,13)$ believe that immunity develops as a result of the aging process rather than from repeated experience with the agent and cite as evidence the fact that the incidence of colds was not reduced in children as a result of attendance at school during the previous year. Furthermore, preschool children living with older school children may be assumed to have had excessive exposure in the recent past but, in spite of this, secondary attack rates for preschool children are similar regardless of whether or not there are school children in the family.

These objections to the development of immunity following colds might be explained by the presence, either simultaneously or in succession, of many antigenically-different viruses capable of producing the common cold.

Observations of the Commission on Acute Respiratory Diseases (14) are more difficult to explain. These investigators rechallenged five volunteers after 19 days with filtrate from a subject with a "severe common cold" and produced colds in four in the initial challenge and four in the rechallenge. Three of the latter four had had a cold on the first challenge.

The explanation of these results, which are contradictory to ours, is not known. It is possible, however, that the dose of nasal washings used was important. In each subject they used $5 \mathrm{ml}$. which was atomized and nebulized into the nose and throat (15). Even so, these investigators stated that, in general, those who had experienced a previous illness as a result of inoculation with the same filtrate suffered from a somewhat milder infection upon reinoculation.

Observations confirmatory to ours were made in chimpanzees by Dochez, Shibley and Mills (16), who stated that these animals could only rarely be infected with secretions from patients with the common cold when challenged within three months after having a previous infection.

The nasal secretion (NS) agents we have reported upon have all failed to grow in animals and in tissue cultures and are believed not to be among the presently known viruses.

Serologic studies of selected pairs of sera from volunteers have shown no relationship of the experimental infections to adeno-viruses, influenza A, B or C, Sendai virus, hemadsorption viruses, chimpanzee coryzal agent (CCA), croup-associated virus (CA), J.H. and 2060 viruses, or polio virus types 1,2 or 3 . These studies are being extended to help clarify the role of the known viruses in the common cold. The identity of the NS agents is being sought and their characterization must ultimately be worked out. At the present time, volunteer studies are essential and can contribute significantly in our understanding of the common viral infections of the respiratory tract. The data 
presented would suggest that the pathogenesis and host response to the common cold are comparable to those that occur in many other specific viral infections.

\section{SUMMARY AND CONCLUSIONS}

The frequency with which the common cold occurred in volunteer subjects who received one of five infectious secretions obtained from patients with common colds or a control buffer solution was as follows:

1. Among 1,034 subjects who received an infectious secretion as an initial challenge, 449 , or 42 per cent, developed colds as compared with 70 , or 10 per cent, of 696 subjects who served as a control population and simultaneously received a buffer solution.

2. Among 73 subjects who developed no cold on initial challenge, 7 , or 10 per cent, developed colds on rechallenge with the same infectious secretion. Among 71 subjects who developed a cold on initial challenge, 6 , or 8 per cent, developed a cold on rechallenge. The interval between challenges varied from 3 to 45 weeks. There was no evidence that the secretions had lost their infectivity between challenges.

3. In contrast, among 74 subjects who developed no cold on initial challenge with an infectious secretion, 31 , or 40 per cent, developed a cold when challenged later with another secretion. Among 41 subjects who developed a cold on initial challenge with an infectious secretion, 19 , or 46 per cent, developed a cold when challenged later with another secretion. The interval between challenges varied from 10 to 74 weeks.

4. It is concluded that the instillation of one of the five infectious secretions obtained from patients with a common cold gave specific protection against the development of a common cold when the same secretion was instilled up to 45 weeks later, whereas there was no protection against a cold produced by any other secretion. These observations suggest that the common cold is caused by a number of different viruses which are antigenically different, and that following infection human subjects develop a specific immunity against the virus which lasts at least for several months.

\section{ACKNOWLEDGMENTS}

We wish to thank the following persons for assistance in this study: Truman O. Anderson, Ph.D.; Arthur V. Boand, Ph.D.; Kenneth Hovland; Tohru Inouye, M.S.; Louise R. Jensen; Jack Saporta; Delores H. Seketa; the late Irwin G. Spiesman, M.D.; Marvin Turck; and Frieda K. Webb.

\section{REFERENCES}

1. Heinbecker, P., and Irvine-Jones, E. I. M. Susceptibility of Eskimos to the common cold and a study of their natural immunity to diphtheria, scarlet fever and bacterial filtrates. J. Immunol. 1928, 15, 395.

2. Paul, J. H., and Freese, H. L. An epidemiological and bacteriological study of the common cold in an isolated arctic community (Spitsbergen). Amer. J. Hyg. 1933, 17, 517.

3. Lidwell, O. M., and Sommerville, T. Observations on the incidence and distribution of the common cold in a rural community during 1948 and 1949. J. Hyg. (Lond.) 1951, 49, 365.

4. Downes, J. Change with age in susceptibility to minor respiratory illness. Milbank mem. Fd Quart. 1952, 30, 211.

5. Badger, G. F., Dingle, J. H., Feller, A. E., Hodges, R. G., Jordan, W. S., Jr., and Rammelkamp, C. H., Jr. A study of illness in a group of Cleveland families. II. Incidence of the common respiratory diseases. Amer. J. Hyg. 1953, 58, 31.

6. Andrewes, C. H. The common cold. Brit. med. Bull. 1953, 9, 206.

7. Jackson, G. G., Dowling, H. F., Spiesman, I. G., and Boand, A. V. Transmission of the common cold to volunteers under controlled conditions. I. The common cold as a clinical entity. A.M.A. Arch. intern. Med. 1958, 101, 267.

8. Jackson, G. G., Dowling, H. F., and Anderson, T. O. Neutralization of common cold agents in volunteers by pooled human globulin. Science 1958, 128, 27.

9. Andrewes, C. H. Adventures among viruses. III. The puzzle of the common cold. New Engl. J. Med. 1950, 242, 235.

10. Gafafer, W. M. The inhabitants of the island of St. Kilda and acute upper respiratory disease. Hum. Biol. 1931, 3, 437:

11. Buck, C. Acute upper respiratory infections in families. Amer. J. Hyg. 1956, 63, 1.

12. Reid, D. D., Williams, R. E. O., and Hirch, A. Colds among office workers; epidemiological study. Lancet 1953, 2, 1303.

13. Badger, G. F., Dingle, J. H., Feller, A. E., Hodges, R. G., Jordan, W. S., Jr., and Rammelkamp, C. H., Jr. A study of illness in a group of Cleveland families. IV. The spread of respiratory infections within the home. Amer. J. Hyg. 1953, 58, 174. 
14. Commission on Acute Respiratory Diseases. Experimental transmission of minor respiratory illness to human volunteers by filter-passing agents. II. Immunity on reinoculation with agents from the two types of minor respiratory illness and from primary atypical pneumonia. J. clin. Invest. 1947, 26, 974.

15. Commission on Acute Respiratory Diseases. Experimental transmission of minor respiratory illness to human volunteers by filter-passing agents. I. Demonstration of two types of illness characterized by long and short incubation periods and different clinical features. J. clin. Invest. 1947, 26, 957.

16. Dochez, A. R., Shibley, G. S., and Mills, K. C. Studies in the common cold. IV. Experimental transmission of the common cold to anthropoid apes and human beings by means of a filtrable agent. J. exp. Med. 1930, 52, 701. 